\title{
Mechanical and Structural Properties of Zinc - Sodium - Phosphate Glasses Doped with $\mathrm{Cu}_{2} \mathrm{O}$
}

\author{
E. Nabhan ${ }^{1, *}$, A. Nabhan ${ }^{2}$, N. Abd El Aal ${ }^{3}$ \\ ${ }^{1}$ Physics Dept., Faculty of Science (Girls), Al Azhar University, Cairo, Egypt \\ ${ }^{2}$ Mechanical Production Dept. Faculty of Engineering, Al Minia University, Al Menia, Egypt \\ ${ }^{3}$ Ultrasonic Laboratory, National Institute of Standard, Giza, Egypt
}

\section{Email address:}

dr.emannabhan@yahoo.com (E. Nabhan)

${ }^{*}$ Corresponding author

\section{To cite this article:}

E. Nabhan, A. Nabhan, N. Abd El Aal. Mechanical and Structural Properties of Zinc - Sodium - Phosphate Glasses Doped with $\mathrm{Cu}_{2} \mathrm{O}$. American Journal of Physics and Applications. Vol. 4, No. 6, 2016, pp. 145-151. doi: 10.11648/j.ajpa.20160406.12

Received: November 5, 2016; Accepted: December 2, 2016; Published: December 20, 2016

\begin{abstract}
Ternary Zinc-Sodium-Phosphate glasses doped with copper of the composition $40 \mathrm{ZnO}-(20-\mathrm{x}) \mathrm{Na}_{2} \mathrm{O}-40 \mathrm{P}_{2} \mathrm{O}_{5}$ $\mathrm{xCu}_{2} \mathrm{O}$ where $\mathrm{x}=0,2,4,6,8$ mol \% were prepared by the tradition quenching method. The effect of $\mathrm{Cu}$ ions on density, molar volume and microhardness has been investigated. FTIR was measured in the range (400-1600) $\mathrm{cm}^{-1}$ to investigate the effect of $\mathrm{Cu}$ ion on the structure of the studied glass. Longitudinal and shear velocities were measured for the studied glass using pulse echo technique. Elastic properties such as longitudinal modulus, shear modulus, bulk modulus, and Young's modulus, Poisson's ratio) and some physical parameters such as softening temperature, hardness, Debye temperature have been calculated. The ultrasonic results and the other measured parameters indicate the $\mathrm{Cu}$ ion increase the cross-link density by the formation of $\mathrm{P}-\mathrm{O}-\mathrm{Cu}$. All the measurements are measured at room temperature.
\end{abstract}

Keywords: Infrared, Infrared Deconvolution, Density, Molar Volume, Hardness, Ultrasonic Velocity, Elastic Moduli

\section{Introduction}

Due to the unique properties of phosphate glasses, such as high thermal expansion coefficient, low melting, softening and transition temperatures, high electrical conductivity (with the addition of transition metal ions), ultraviolet and far infrared transmission and other optical characteristics, make them of great scientific and technical interest for many applications [1-4]. However, the poor chemical durability is one of the disadvantages of which limit its use in many applications [5,6]. The addition of one or more of the transition metal oxide to phosphate glass has improved the chemical durability [7]. With the Addition of $\mathrm{ZnO}$ to phosphate glass has an effect on the chemical durability and other properties that, when it adds as a modifier, it increases the cross-link between phosphate anions, inhabiting hydration reaction $[8,9]$. Additionally, $\mathrm{ZnO}$ improves the melting properties that, it is lowering the melting and transition temperatures, and also improve the opacity of glass, which make it is important for many applications such as glass filters and as sealing glass. Also adding copper to phosphate glasses maintains optical absorption band in the visible -near IR region makes it a candidate as band pass filter [10], and also $\mathrm{Cu}$ ions exhibiting a semiconducting properties [11]. In different glasses, copper can exist in two states, as divalent $\mathrm{Cu}^{2+}$ which give the glass color from blue to green depending on its concentration or monovalent $\mathrm{Cu}^{+}$ (Cuprous) which doesn't produce color because its five dorbital occupied or containing both states. Their ratio of $\mathrm{Cu}^{+}$ and $\mathrm{Cu}^{2+}$ depending on the type of glass former, composition and thermal history (such as environment, melting temperature, and melting time) [12]. Recently, $\mathrm{Cu}^{2+}$ ions doped glasses have shown a great importance because of their optical stability and variable optical and electrical applications [13, 14]

The mechanical properties such as elastic moduli, and other mechanical properties are of great importance because it gives a good information concerning the forces that are operative between atoms of the solid and also it suitable for describing the compactness of the glass structure $[15,16]$. 
The main objective of this work is to investigate FTIR, density, molar volume, hardness, and elastic properties of some Zinc-sodium-phosphate-glasses doped with different concentrations of copper oxide up to $8 \mathrm{~mol} \%$. It is amid to study the effect of $\mathrm{Cu}_{2} \mathrm{O}$ on the different physical properties which makes it candidate for many applications, such as glass to metal seals.

\section{Experimental Procedure}

\subsection{Preparation of Glasses}

The glass samples with chemical $40 \mathrm{ZnO}-(20-\mathrm{x}) \mathrm{Na}_{2} \mathrm{O}-$ $40 \mathrm{P}_{2} \mathrm{O}_{5}-\mathrm{xCu}_{2} \mathrm{O}$ in molar ratio $\mathrm{x}=0,2,4,6$, and 8 were prepared by the conventional melt and quenching technique. Batches were prepared from appropriate mixtures of reagent grade $\mathrm{NaCO}_{3}, \mathrm{ZnO}, \mathrm{NH}_{4} \mathrm{H}_{2} \mathrm{PO}_{4}$ and $\mathrm{Cu}_{2} \mathrm{O}$. The batches were mixed and grinding using porcelain mortar and then calcinated in porcelain crucible using muffle furnace for about $1 \mathrm{~h}$ at $350^{\circ} \mathrm{C}$, then it heated at $1050^{\circ} \mathrm{C}$ for $1 \mathrm{~h}$. The melt were removed from the furnace several times and shacked well to ensure homogeneity. The melting were poured in a preheated copper moldand annealed at $300^{\circ} \mathrm{C}$. the sample that free of copper is transparent and Colorless, while with the addition of $\mathrm{Cu}_{2} \mathrm{O}$ the sample were transparent and colored. The color of samples changes from blue to green gradually as $\mathrm{Cu}_{2} \mathrm{O}$ content increase.

\subsection{Infrared Measurements}

The infrared absorption spectra of the studied glasses were measured at room temperature using Beckman 4250 IR spectrometer in the range (400-4000) $\mathrm{cm}^{-1}$, using the $\mathrm{KBr}$ pellet technique. The resulting IR spectra have been deconvoluted in order to know further information about the structural groups and their changes.

\subsection{Density Measurements}

Densities of all studied glass samples were measured at room temperature by applying Archimedes Principle using carbon tetrachloride as buoyant liquid using the relation:

$$
\rho=\frac{w_{a}}{w_{a}-w_{b}} \rho_{b}
$$

Where $w_{a}$ and $w_{b}$ the weights of sample in air and buoyant respectively. $\rho_{b}$ is the density of the buoyant which equal $1.593 \mathrm{gm} / \mathrm{cm}^{3}$. The molar volume $V_{m}$ of each sample was being calculated using the formula:

$$
V_{m}=\frac{\Sigma M_{i} N_{i}}{\rho}
$$

Where $M_{i}$ is the molecular weight of the constituent oxides, and $N_{i}$ is the percent composition of the constituent oxides and $\rho$ is the density.

\subsection{Microhardness Measurements}

The microhardness of the samples were determined using a microhardness tester of the type Shimadzu (Japan). High polishing was necessary for obtaining smooth, flat parallel surfaces before indentation testing. Ten indentations were measured for each sample. The appropriate loading of the studied samples is $200 \mathrm{gm}$ for $15 \mathrm{sec}$. The microhardness value was calculated automatically.

\subsection{Ultrasonic Measurements}

The longitudinal and shear ultrasonic wave velocity $V_{l}$ and $V_{s}$ respectively, were measured at room temperature using pulse-echo method. X cut and Y cut transducers operated at a fundamental frequency of $4 \mathrm{MHz}$ and a digital flaw detector (USIP 20, Krauthramer, Germany) were used, the velocity was calculated using the relation

$$
V=\frac{2 d}{\Delta t}
$$

Where $d$ is the sample thickness, $\Delta t$ is the time interval.

\section{Determination of Elastic Moduli}

The longitudinal and shear ultrasonic wave velocity $V_{l}$ and $V_{s}$ were calculated using equation (3). Then the elastic strains produced by a small stress can be described by the longitudinal modulus $(L)$ and shear modulus $(S)$ given by

$$
\begin{aligned}
& \mathrm{L}=\rho \mathrm{V}_{\mathrm{l}}^{2} \\
& \mathrm{~S}=\rho \mathrm{V}_{\mathrm{s}}^{2}
\end{aligned}
$$

Where $\rho$ is the density of the studied glass samples.

Young's modulus $(E)$, the bulk modulus $(K)$, Poisson's ratio $(\sigma)$ and the microhardness $\left(H_{w}\right)$ can be calculated using the following equations [17]

$$
\begin{gathered}
K=L-\left(\frac{4 S}{3}\right) \\
\mathrm{E}=(1+\sigma) 2 \mathrm{~S} \\
\sigma=\frac{\left(V_{l}^{2}-2 V_{s}^{2}\right)}{2\left(V_{l}^{2}-V_{s}^{2}\right)} \\
H_{u}=\frac{(1-2 \sigma) E}{6(1+\sigma)}
\end{gathered}
$$

Other parameters can be calculated using the ultrasonic velocities and the experimental density, Debye temperature $\Theta_{D}$, the mean velocity and the softening temperature.

The mean sound velocity $V_{\text {mean }}$ has the expression

$$
V_{\text {mean }}=\left[\frac{1}{3}\left(\frac{1}{V_{l}^{3}}+\frac{2}{V_{s}^{3}}\right)\right]^{-\frac{1}{3}}
$$

Then the Debye temperature can be expressed interims of the mean velocity

$$
\theta_{D}=\left(\frac{h}{k_{B}}\right)\left(\frac{3 N_{A} \Psi}{4 \pi V_{m}}\right)^{\frac{1}{3}} V_{\text {mean }}
$$


Where, $h$ is Plank's constant, $k_{B}$ is Boltzman constant, $N_{A}$ is Avogadro's number, $\Psi$ is the number of atoms in the chemical formula, $V_{m}$ is the molar volume.

Softening temperature $T_{s}$ can also be calculated using the shear ultrasonic velocity by the equation:

$$
T_{s}=\frac{V_{s}^{2} M}{C^{2} \Psi}
$$

Where $\mathrm{M}$ is the molecular weight, and $\mathrm{C}$ is a constant of value $507.4 \mathrm{~m} \mathrm{~s}^{-1} \mathrm{k}^{-1}$ for alumina-silicate glasses and assumed to be the same for all glasses.

\section{Results and Discussions}

\subsection{IR Results and Discussion}

The IR spectra of the studied glass samples are represented in Figure (1) as the $\mathrm{Cu}_{2} \mathrm{O}$ content increases from 0.0 up to 8.0 $\mathrm{mol} \%$, these values being reported in the following as the $\mathrm{G} 0$, G1..., G8. Inspection of the spectra shows that these spectra are almost similar without any significant differences except in a slight shift of band positions and sometimes changes in the relative intensities of the main bands. Based on information predicted from previous studies $[18,19]$ leads to the following assignments:

- The band at $500 \mathrm{~cm}^{-1}$ which can be assigned as the deformation vibration of $\mathrm{PO}_{4}{ }^{3-}$ group is slightly shifted to higher as $\mathrm{Cu}_{2} \mathrm{O}$ increase from glass $\mathrm{G}_{0}$ to $\mathrm{G}_{8}$.

- The band at $750 \mathrm{~cm}^{-1}$ which is attributed to P-O-P symmetric band is slightly shifted to higher wavenumber as $\mathrm{Cu}_{2} \mathrm{O}$ content increase from glass $\mathrm{G}_{0}$ to $\mathrm{G}_{8}$

- The band at about $900 \mathrm{~cm}^{-1}$ which is assigned to P-O-P asymmetric, is slightly shifted to higher wave number as $\mathrm{Cu}_{2} \mathrm{O}$ content increase from glass $\mathrm{G}_{0}$ to $\mathrm{G}_{8}$.

- The two absorption bands at 1000 and $1100 \mathrm{~cm}^{-1}$ are

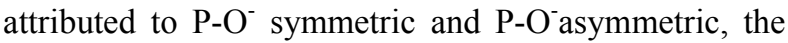
phosphate -non bridging oxygen portion in $\mathrm{PO}_{4}$ tetrahedra in a chain structure respectively. The symmetric band $\mathrm{P}-\mathrm{O}-_{\text {sym }}$ doesn't affect by $\mathrm{Cu}_{2} \mathrm{O}$ content while the P-O- ${ }_{\text {asy }}$ there is a decrease in the intensity and the band become more broadening and its center slightly shifted to higher wavenumber as $\mathrm{Cu}_{2} \mathrm{O}$ increase.

- The shoulder which observed at $1270 \mathrm{~cm}^{-1}$ is assigned to asymmetric stretching modes of the two non bridging oxygens bonded to phosphorus atoms-O-P-O units in the phosphate tetrahedral[20,21]. It is noticed that its intensity decrease and seems to overlap with the P-O- asy as $\mathrm{Cu}_{2} \mathrm{O}$ content increase. From the spectra, it is clear that the IR spectra are free from any characteristic absorption bands of $\mathrm{ZnO}$ or $\mathrm{Cu}_{2} \mathrm{O}$ as network formers which means that both of them play the role of network modifiers and so it occupy the interstices.

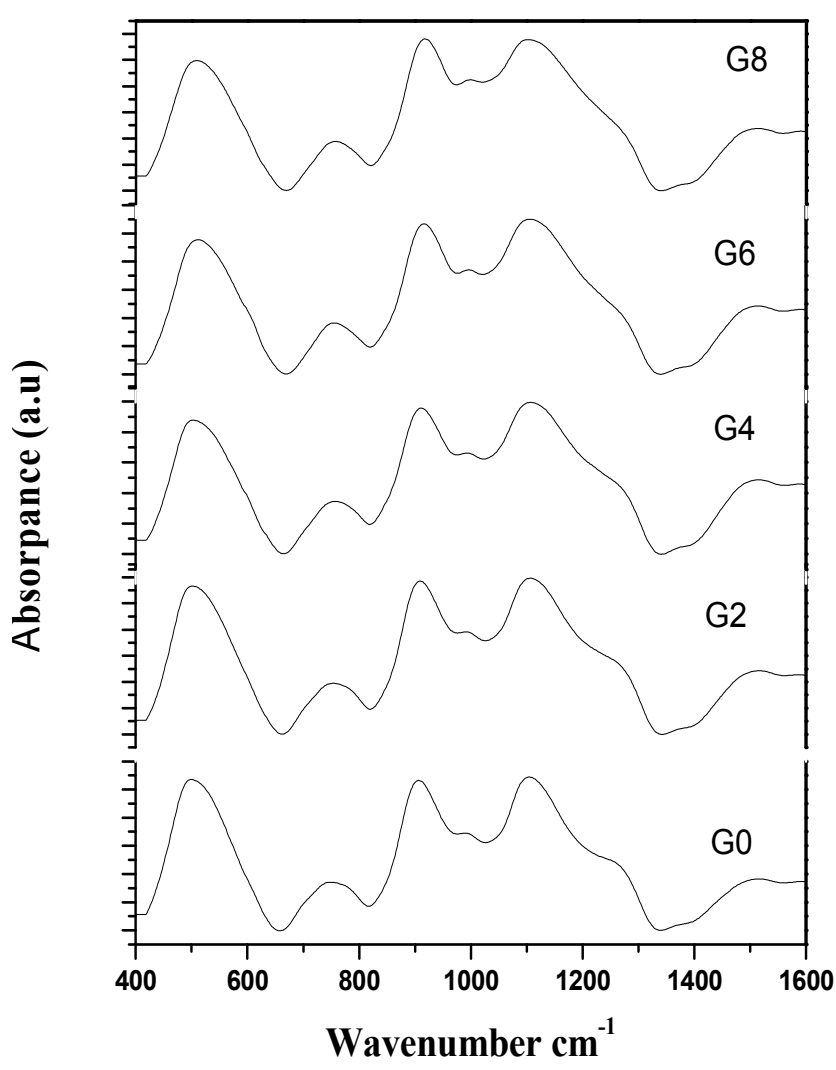

Figure 1. The IR spectra of 40ZnO-(20-x) $\mathrm{Na}_{2} \mathrm{O}-40 \mathrm{P}_{2} \mathrm{O}_{5}-\mathrm{xCu} \mathrm{Cu}_{2} \mathrm{O}$ glass system. $G_{0}, G_{2}, G_{4}, G_{6}$, and $G_{8}$ for $\mathrm{Cu}_{2} \mathrm{O}=0,2,4,6$, and 8 mol \% respectively.

From the results of the IR, the shift of the two bands at 740 and $900 \mathrm{~cm}^{-1}$ of the P-O-P sym and P-O-P asy respectively to higher wavenumber may be due the increase of the covalence character of these bands indicates that the bonds are strengthened as $\mathrm{Na}_{2} \mathrm{O}$ is replaced by $\mathrm{Cu}_{2} \mathrm{O}$ in agreement with Shin et al.[22] and Chahine et al [23]. The decrease in intensity of the band at

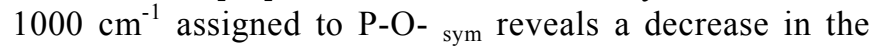
non-bridging oxygen and increase in the cross-link density as $\mathrm{Na}_{2} \mathrm{O}$ is replaced by $\mathrm{Cu}_{2} \mathrm{O}$. This suggestion is in agreement with the results of Gresh et al [24], who suggested that $\mathrm{M}^{2+}$ cations increase the cross-link density without breaking P-O-P chains. In other words $\mathrm{Cu}$ cations decrease the non-bridging oxygen and increase the crosslink density by the formation of $\mathrm{P}-\mathrm{O}-\mathrm{Cu}$ bonds which increase the cross-link density. A deconvolution process, as described elsewhere [25], should be performed to get further information about the characteristic parameters such as the band centers (C), which is related to some type of vibration specific structural groups, its width (W) and relative area (A), which is proportional to the concentration ratio of this structural group. The deconvolution parameters of the band for the investigated glasses are given in Table [1]. Figure (2) illustrates the deconvoluted spectra of sample G2 as an example. 
Table 1. Deconvolution parameters of the infrared spectra of the studied glasses.

\begin{tabular}{lllllll}
\hline & C & 754 & 906 & 987 & 1111.6 & 1249 \\
G0 & W & 103.7 & 70.7 & 61.7 & 119.8 & 82 \\
& A & 0.11 & 0.24 & 0.10 & 0.42 & 0.12 \\
& C & 757 & 909 & 987 & 1113.8 & 1253 \\
G2 & W & 104 & 70 & 60 & 131 & 79 \\
& A & 0.11 & 0.24 & 0.09 & 0.45 & 0.11 \\
& C & 760 & 911 & 991 & 1114 & 1257 \\
G4 & W & 97.9 & 78 & 49.9 & 150 & 73 \\
& A & 0.11 & 0.25 & 0.05 & 0.51 & 0.08 \\
& C & 760 & 915 & 996 & 1113 & 1258 \\
G6 & W & 86 & 81 & 40 & 160 & 67 \\
& A & 0.098 & 0.26 & 0.03 & 0.56 & 0.058 \\
& C & 761 & 916 & 996 & 1111 & 1259 \\
G8 & W & 89 & 182 & 40 & 182 & 60 \\
& A & 0.096 & 0.23 & 0.03 & 0.60 & 0.038 \\
\hline
\end{tabular}

$\mathrm{C}$ is the center of the band $\left(\mathrm{cm}^{-1}\right), \mathrm{W}$ is the band width $\left(\mathrm{cm}^{-1}\right)$ and $\mathrm{A}$ is the relative area(\%) of the component band.

From the deconvolution data, of the studied glass system, represented in Table[1], the band centered at $754 \mathrm{~cm}^{-1}$, which due to P-O-P ${ }_{\text {sy }}$, its center shifted to higher wave number as $\mathrm{Na}_{2} \mathrm{O}$ is replaced by $\mathrm{Cu}_{2} \mathrm{O}$. While its relative intensity remains constant. The band centered at $907 \mathrm{~cm}^{-1}$ which is due to $\mathrm{P}-\mathrm{O}-\mathrm{P}$ asy shifted to higher wavenumber and its relative intensity increases as $\mathrm{Cu}_{2} \mathrm{O}$ increases. The results of the two bands reveal that as $\mathrm{Na}_{2} \mathrm{O}$ is replaced by $\mathrm{Cu}_{2} \mathrm{O}$ the cross-link density increase due to the formation of $\mathrm{P}-\mathrm{O}-\mathrm{Cu}$ which indicated from the increase of the relative intensity of P-O-P asy. There is also increasing in the bond strength of both the $\mathrm{P}-\mathrm{O}-\mathrm{P}_{\text {sy }}$ and P-O-P $\mathrm{P}_{\text {asy }}$ due to the shift to higher wavenumber.

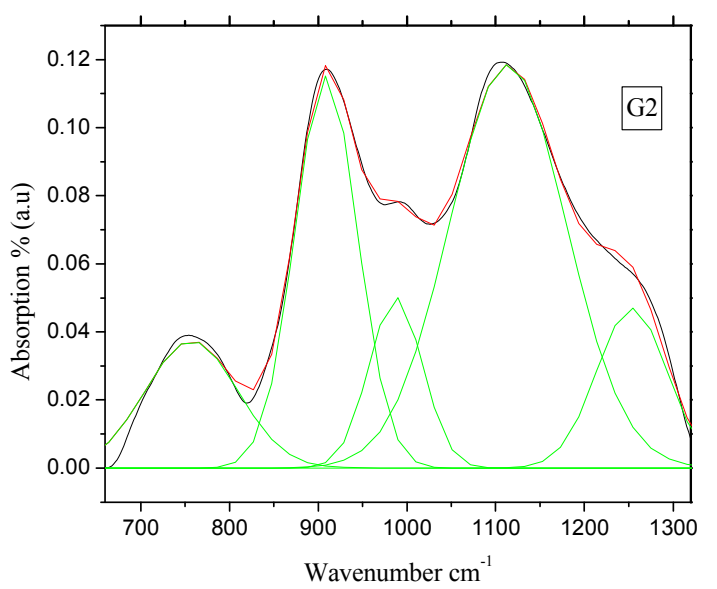

Figure 2. Band deconvolution of IR spectrum for glass sample G2. The red line shows the fit of IR spectra of G2.

The band at $987 \mathrm{~cm}^{-1}$, which is related to the non-bridging oxygen atoms $\mathrm{P}^{-} \mathrm{O}^{-}$, shifted to higher wavenumber and its relative intensity decrease as $\mathrm{Na}_{2} \mathrm{O}$ is replaced by $\mathrm{Cu}_{2} \mathrm{O}$, which means the increase in the cross-link density and decreasing in the non-bridging oxygen atoms.

\subsection{Density and Molar Volume}

Table 2. The compositions, experimental density, experimental molar volume, and the microhardness.

\begin{tabular}{|c|c|c|c|c|c|c|c|}
\hline \multirow{2}{*}{ Sample no. } & \multicolumn{4}{|c|}{ Composition in mol \% } & \multirow{2}{*}{ Exp. Density gm/ $/ \mathrm{cm}^{3}$} & \multirow{2}{*}{ Exp. Molar volume } & \multirow{2}{*}{ Hardness $\mathrm{kg} / \mathrm{mm}^{2}$} \\
\hline & $\mathrm{ZnO}$ & $\mathrm{Na}_{2} \mathrm{O}$ & $\mathbf{P}_{2} \mathbf{O}_{5}$ & $\mathrm{Cu}_{2} \mathrm{O}$ & & & \\
\hline $\mathrm{G}_{0}$ & 40 & 20 & 40 & 0 & 3.027 & 33.61 & 344 \\
\hline $\mathrm{G}_{2}$ & 40 & 18 & 40 & 2 & 3.084 & 33.51 & 355 \\
\hline $\mathrm{G}_{4}$ & 40 & 16 & 40 & 4 & 3.161 & 33.38 & 366 \\
\hline $\mathrm{G}_{6}$ & 40 & 14 & 40 & 6 & 3.204 & 33.27 & 375 \\
\hline $\mathrm{G}_{8}$ & 40 & 12 & 40 & 8 & 3.281 & 32.98 & 387 \\
\hline
\end{tabular}

Table [2] display the composition of the studied glass samples and their experimental density $\rho$, molar volume $V_{m}$ and the Vickers microhardness $H$. The data of both density and molar volume as a function of $\mathrm{Cu}_{2} \mathrm{O}$ content have been represented in Figure (3). From the figure density increase as $\mathrm{Cu}_{2} \mathrm{O}$ content while the molar volume decreases.

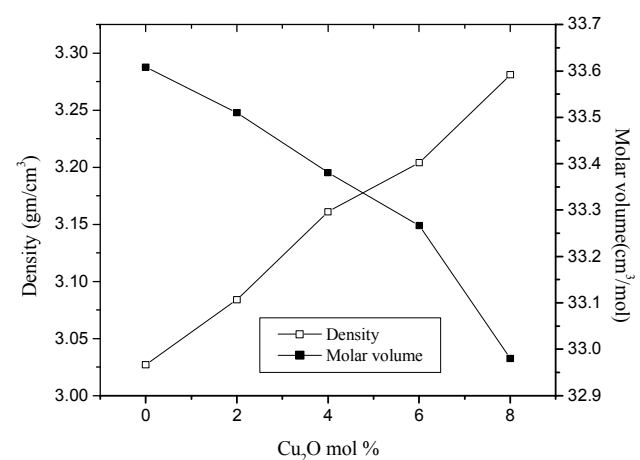

Figure 3. The relation between $\mathrm{Cu}_{2} \mathrm{O}$ mol \% and both the density and molar volume of the studied glasses.
The increase of the density as $\mathrm{Cu}_{2} \mathrm{O}$ increase is related to the difference in atomic mass of $\mathrm{Cu}$ ion and $\mathrm{Na}$ ion [26] while the decrease of the molar volume may be due to the less ionic character of $\mathrm{Cu}-\mathrm{O}$ than that of $\mathrm{Na}-\mathrm{O} \quad(0.53$ and 0.82 respectively) as calculated from Pauling [27]. This means that the increase in the covalence character of the system as $\mathrm{Cu}_{2} \mathrm{O}$ increase on the expense of $\mathrm{Na}_{2} \mathrm{O}$. The results of the density and molar volume reveals that as $\mathrm{Na}_{2} \mathrm{O}$ is replaced by $\mathrm{Cu}_{2} \mathrm{O}$ the glass structure becomes more compacted. Such compaction can be realized through any of the following changes:

- Shortening of the bond length as indicated by the observed shift of P-O-P symmetric and asymmetric stretching vibrations at 750 and $900 \mathrm{~cm}^{-1}$ respectively towards higher wavenumber.

- The role of $\mathrm{Cu}_{2} \mathrm{O}$ cation in crosses linking the phosphate groups.

- Occupation of interstices as also concluded from IR results. 


\subsection{Microhardness}

Figure (4) shows that the hardness of the studied glass samples as a function of $\mathrm{Cu}_{2} \mathrm{O}$ content and the data are represented in Table [2]. From the figure the value of the hardness is found to increase as $\mathrm{Cu}_{2} \mathrm{O}$ content increase. It is known that the hardness increases as the flow mobility of the matrix element decrease. This was supported by the conclusion obtained from the viscosity studies of Fen et. al. [28]. He suggested that an increase in the hardness number of different oxides is attributed to the decrease in the flow mechanism in a glass containing oxides. Decrease in the flow mobility is expected to occur in replacing $\mathrm{Na}_{2} \mathrm{O}$ by $\mathrm{Cu}_{2} \mathrm{O}$ due to the decrease in the non-bridging oxygen atoms resulting from the increasing of the cross-link density as well as the remarkable difference of $\mathrm{Na}$ atomic mass and the atomic mass of $\mathrm{Cu}$ and consequently the hardness increase.

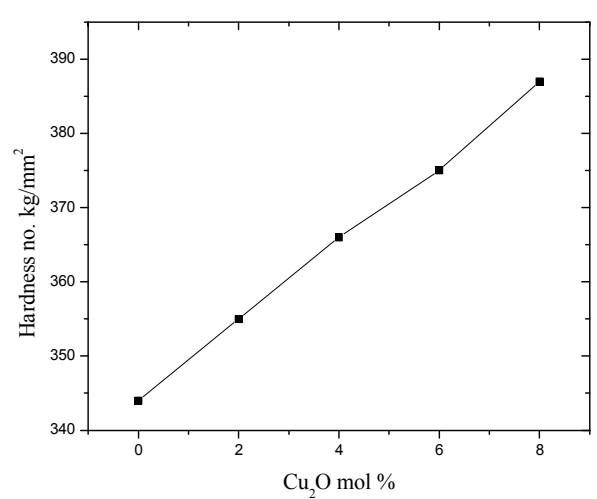

Figure 4. The relation between $\mathrm{Cu}_{2} \mathrm{O}$ mole \% and the experimental Vicker's microhardness of the studied glasses.

\subsection{Ultrasonic Measurements}

The experimentally measured ultrasonic velocities $V_{l}$ and $V_{s}$ together with the corresponding evaluated parameters $(L$, $S, E, K, \sigma, V_{\text {mean, }} \Theta_{D}, T_{s}$ and $H$ ) are given in Table [3].

Table 3. The values of the density $\rho$, longitudinal velocity $V_{l}$, shear velocity $V_{s}$, shear modulus $S$, Longitudinal modulus L, bulk modulus $K$, Younge's modulus $E$, Poisson's ratio $\sigma$, Hardness $H u$, softening temperature $T_{s}$, Debye temperature $\theta_{D}$.

\begin{tabular}{|c|c|c|c|c|c|c|c|c|c|c|c|}
\hline Sample no. & Density $\mathrm{Kg} / \mathrm{m}^{3}$ & $\mathrm{Vl} \mathrm{m} / \mathrm{sec}$ & $\mathrm{Vs} \mathrm{m} / \mathrm{sec}$ & $S G P a$ & $L G P a$ & $K G P a$ & $E G P a$ & $\bar{\sigma}$ & $\mathrm{Hu} \mathrm{Kg} / \mathrm{mm}^{2}$ & $T_{s}{ }^{0} k$ & $\boldsymbol{\theta}_{D}{ }^{0} k$ \\
\hline G0 & 3027 & 4716 & 2543 & 19.58 & 67.32 & 41.22 & 50.70 & 0.295 & 267 & 537 & 371 \\
\hline $\mathrm{G} 2$ & 3084 & 4800 & 2586 & 20.62 & 71.06 & 43.55 & 53.44 & 0.296 & 281 & 565 & 378 \\
\hline G4 & 3144 & 4856 & 2595 & 21.17 & 74.13 & 45.90 & 55.30 & 0.300 & 282 & 578 & 380 \\
\hline G6 & 3204 & 4919 & 2609 & 21.82 & 77.52 & 48.44 & 56.90 & 0.300 & 284 & 593 & 383 \\
\hline G8 & 3281 & 4935 & 2637 & 22.81 & 79.00 & 49.48 & 59.33 & 0.300 & 303 & 615 & 388 \\
\hline
\end{tabular}

The effect of replacing progressive mol ratio of $\mathrm{Na}_{2} \mathrm{O}$ by $\mathrm{Cu}_{2} \mathrm{O}$ of the studied glass samples on the different parameters is represented in Figure (5, 6, 7, 8 and 9).

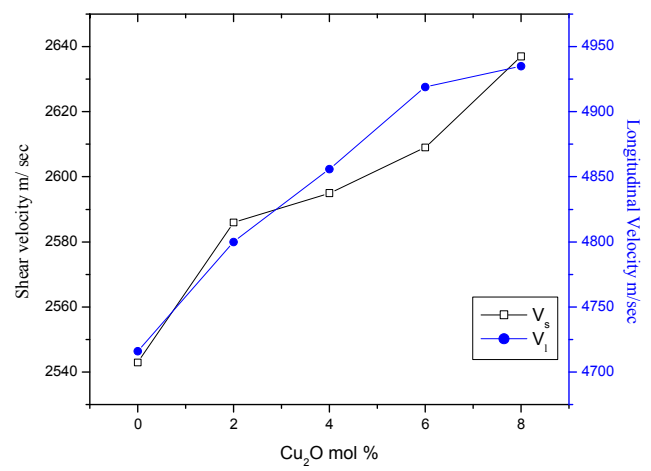

Figure 5. The relation between $\mathrm{Cu}_{2} \mathrm{O}$ content and the longitudinal and shear velocity $V_{l}$ and $V_{s}$ respectively

Inspection of these relations reveals that, Form Figure (5).

Each of the longitudinal velocity $V_{l}$, transverse velocity $V_{s}$ are progressively increased as $\mathrm{Na}_{2} \mathrm{O}$ is replaced by $\mathrm{Cu}_{2} \mathrm{O}$. It is obvious that the increase in the cross link density and the decrease in the non bridging oxygen and so the increase in connectivity will reflect on the ultrasonic velocities to increase in agreement with the results obtained from the above result ( IR, density, molar volume, and hardness)by the formation of $\mathrm{P}-\mathrm{O}-\mathrm{Cu}$ which decrease the non bridging oxygen atoms and increase both of the cross-link density and the covalency of the bonds. This also will reflect on the chemical durability and enhance it to increase with increasing $\mathrm{Cu}_{2} \mathrm{O}$.

Figure (6) represented the relation between $\mathrm{Cu}_{2} \mathrm{O}$ content and the different elastic moduli (L, E, K, and S). From the figure all the elastic moduli increase with increasing $\mathrm{Cu}_{2} \mathrm{O}$ content for the same reasons that reflect on the shear and longitudinal velocities and in agreement with results obtained from the other results.

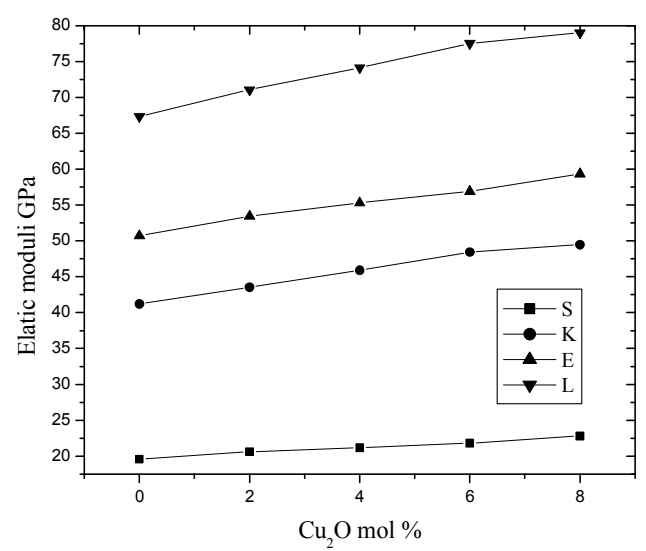

Figure 6. The relation between the elastic moduli ( $S, L, K$ and $E)$ with the $\mathrm{Cu}_{2} \mathrm{O}$ content.

The variation of Debye temperature $\Theta_{D}$, softening temperature $\mathrm{T}_{\mathrm{s}}$ with $\mathrm{Cu}_{2} \mathrm{O}$ content is represented in Figure (7). The Debye temperature at which nearly all mode of vibrations in the solid are excited and it is increasing as the 
rigidity of the system. From the figure it is clear that $\Theta_{D}$ increase with the increase of $\mathrm{Cu}_{2} \mathrm{O}$ content, which means that the rigidity of the glass system increase as $\mathrm{Cu}_{2} \mathrm{O}$ increase.

The softening temperature and hardness which represented in Figure (7), Figure (8) are also affected by the rigidity of the system, the rigidity increases as the non bridging oxygen decreases, the cross-link density increases, and with the strengthening of the bonds, all of these increased as $\mathrm{Cu}_{2} \mathrm{O}$ increase in agreement with Marzouk[18].

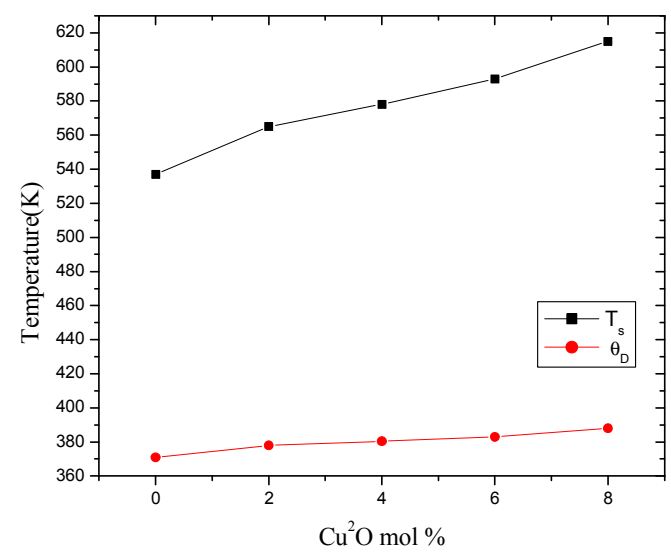

Figure 7. The relation between Debye temperature, softening temperature and $\mathrm{Cu}_{2} \mathrm{O}$ content.

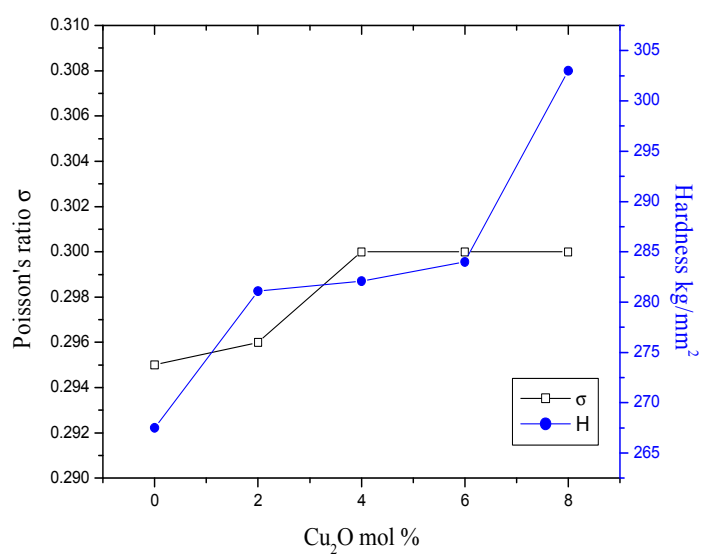

Figure 8. The relation between ultrasonic hardness, Poisson's ratio and $\mathrm{Cu}_{2} \mathrm{O}$ content.

Poisson's ratio $\sigma$ with $\mathrm{Cu}_{2} \mathrm{O}$ content is represented in Figure (8). The value of $\sigma$ is varied from 0.295 to 0.300 as $\mathrm{Cu}_{2} \mathrm{O}$ content increase from 0 to $8 \mathrm{~mol} \%$ is almost negligible in agreement with Rajendran et.al.[29] who neglect the variation of $\sigma$ in the range from about 0.27 to about 0.29 as $\mathrm{SiO}_{2}$ increase.

\section{Conclusions}

Studies of IR, density, molar volume, hardness, ultrasonic velocities, elastic moduli and other parameters such Debye temperature, softening temperature, hardness and poisson's ratio as $\mathrm{Na}_{2} \mathrm{O}$ is replaced by $\mathrm{Cu}_{2} \mathrm{O}$ in zinc sodium phosphate glasses were carried out. Infrared absorption spectra indicate that the cross-link density of the glassy system increase by the decrease in the number of non-bridging oxygen atoms, the formation of $\mathrm{P}-\mathrm{O}-\mathrm{Cu}$ bonds, and the increase of the covalence character of bonds. Which also causes strengthening of the bonds as $\mathrm{Cu}_{2} \mathrm{O}$ content increase. The IR results have been ascertained by the deconvolution of the IR spectra of the samples. Both the density and hardness increase with increasing $\mathrm{Cu}_{2} \mathrm{O}$ content, while the molar volume decreases. The increases in the longitudinal and shear velocities, Debye temperature, softening temperature, hardness, and elastic moduli, are attributed to the increase of the connectivity of the system.

\section{References}

[1] A. Bhide, K. Hariharan, Mater. Chem. Phys. 105 (2007) 213.

[2] R. K. Brow, J. Non-Cryst. Solids, 263-264 (2000) 1.

[3] J. A. Wilder, J. Non-Cryst. Solids, 38-39 (1980) 879.

[4] I. Abrahams, E. Hadzifejzovic, Solid State Ionics, 134 (2000) 249.

[5] H. Yung, P. Y. Shin, H. S. Liu, T. S. Chin, J. Am. Ceram. Soci. 80 (1997) 2213.

[6] M. R. Reidmeyer, M. Rajaram, D. E. Day. J. Non-Cryst. Solids, 85 (1986) 186.

[7] S. T. Reis, M, Karabulut, D. E. Day, J. Non-Cryst. Solids, 292 (2001) 150 .

[8] D. Carta, J. C. Knowles, P. Guerry, M. E. Smith, R. J. Newport, J. Mater. Chem. 19 (2009) 150.

[9] P. Pascuta, G. Borodi, N. Jumate, I. Vida-Simiti, D. Viorel, E, Culea. J. Alloys Comp. 504 (2010) 479.

[10] B. S. Bea. M. C. Weinberg, J. Appl. Phs. 73 (1993) 7760.

[11] K. J. Rao Structural Chemistry of Glasses, El Sevier, 2002.

[12] E. I. Kamitsos, J. Mater. Sci. 11 (1976) 925-928

[13] A. Thulasiramudu, S. Buddhudu. J Quant Spectrosc Radiat Trans 2006; 97: 181-94.

[14] G. Lakshminarayana, S. Buddhudu. Spectrochim Acta Part A 2005; 62: 364-71.

[15] G. M. Bartenev. Structural and Mechanical Properties of Inorganic Glasses, Wolters-Nordho, Groningen. The Netherlands, 1970.

[16] C. Narayana Reddy, V. C. Veeranna Gowda, R. P. Sreekanth Chakradhar. J. Non-Cryst. Solids 354 (2008) 32.

[17] A. F. L. Almeida, D. Thomazini, I. F. Vasconcelos, M. A. Valente, A. S. B. Sombra, Int. J. Inorg. Mater. 3 (2001) 829.

[18] Samir. M. Marzouk, Mater. Chem. Phys. 114 (2009) 188.

[19] Y. M. Moustafa, E. El. Egili, J. Non-Cryst. Solids, 240 (1998) 144.

[20] R. K. Brow, D. R. Tallant, K. Meyer, C. C. Phifer, J. NonCryst. Solids 191 (1995) 45-55.

[21] K. Meyer, J. Non-Cryst. Solids 209 (1997) 227-239. 
[22] P. Y. Shin, T. S. Shin, J. Non-Cryst. Solids, 260 (1998) 50-57.

[23] A, Chahine, M. Et-Tabirou, M. El Benaissi, M. Haddad, J. L. Pascal, Mater. Chem. Phys. 84 (2004) 341-347.

[24] R. Gresch, W. Muller-Warmuth, H. Dutz, J. Non-Cryst. Solids 34, (1979) 127.

[25] Y. Moustafa, H. Doweidar, G. El-Damrawi, Phys. Chem. Glasses 35 (1994) 104.
[26] H. Elhaes, M. Attallah, Y. Elbashar, M. El-Okr, M. Ebrahim, Physica B 449 (2014) 251-254.

[27] L. Pauling, in The Nature of Chemical Bond, Cornell University Press (1960) 98.

[28] Fin, Linzhang, J. Non-Cryst. Solids 42 (1980) 142.

[29] V. Rajendran, A. Nashara Begum, M. A. Azooz, F. H. El Batal, Biomateriales, 23 (2002) 4263-4275. 